Bangladesh Journal of Neuroscience 2015; Vol. 31 (1): 50-55

\title{
Myasthenia gravis as a presenting feature in a patient with SCLC: A case report

\author{
RUMANAHABIB ${ }^{1}$,MD. RASHEDUL ISLAM ${ }^{2}$, AMINUR RAHMAN ${ }^{3}$, NIRMALENDU BIKASH $^{\prime}$ \\ BHOWMIK ${ }^{4}$, MD. AMIRUL HAQUE ${ }^{5}$
}

\begin{abstract}
:
Small cell lung cancer (SCLC) is the most frequent cancer histology associated with paraneoplastic syndromes. These syndromes are typically caused by ectopic hormone production or immune-mediated tissue destruction caused by neural antigen expression from cancer cells. Lambert-Eaton myasthenic syndrome is well known to be a classical paraneoplastic syndrome of small cell lung carcinoma (SCLC). Only a few cases of myasthenia gravis (MG) and SCLC were previously reported. The causal association between lung cancer and non-thymomatous myasthenia gravis has not been clarified yet. To date, there has been no evidence supporting the speculation that association of myasthenia gravis with lung cancer might be one of the phenotypes of paraneoplastic syndrome. We present a case of a 47-year-old male ex-smoker with $S C L C$ associated with myasthenia gravis evidenced by the clinical findings of ptosis, dysphagia, proximal weakness, and positive repetitive nerve stimulation (RNS) test.

Abbreviation: MG(myasthenia gravis), SCLC(Small cell lung cancer), RNS (repetitive nerve stimulation), NMJ (neuromuscular junction), LEMS(Lambert-Eaton myasthenic syndrome). (LEMS),
\end{abstract}

\section{Introduction:}

Myasthenia gravis is an autoimmune neuromuscular disease caused by autoantibodies to postsynaptic acetylcholine receptors, blocking their attachment at the postsynaptic junction. This results in a lack of the excitatory effects of acetylcholine at the postsynaptic nicotinic receptors. MG is considered as a paraneoplastic syndrome associated with thymoma in $15 \%$ of $M G$ patients. Extrathymic malignancies have been also reported to happen simultaneously with MG ${ }^{1-5}$. Here we reported this case of lung cancer presenting with postsynaptic NMJ disorder (MG).

\section{Case Report:}

A 47 years old diabetic, hypertensive, ex-smoker gentleman got admitted under Neurology Unit II with the complains of progressive weakness of both upper and lower limbs for one month and difficulty in swallowing of liquid food for ten days. He also gave history of weight loss in past six months but had no change in bowel and bladder functions, muscle twitching and gave no preceding history of anorexia , fever, cough or hemoptysis

On examination, the patient was ill looking with below average body built. His vitals signs were normal. A hard, non tender, immobile swelling was noted over thye sternum. On neurological examination, he had dysarthia , nasal intonation, ptosis on right side, left facial weakness, absent gag reflex and palatal palsy. Muscle power was $4 / 5$, reflexes were normal and planters were bilaterally flexor. He had diminished ability and difficulty to sustain upward gaze for greater than 20 seconds. The patient was unable to maintain a sustained hold against gravity of the upper extremities while holding the arm in an outstretched position ( Fig-1).

1. Assistant Professor, Department of Neurology, BIRDEM General Hospital, Dhaka.

2. Registrar, Department of Neurology, BIRDEM General Hospital, Dhaka.

3. Consultant, Department of Neurology, BIRDEM General Hospital, Dhaka.

4. Professor, Department of Neurology, BIRDEM General Hospital, Dhaka.

5. Professor \& Head, Department of Neurology, BIRDEM General Hospital, Dhaka. 

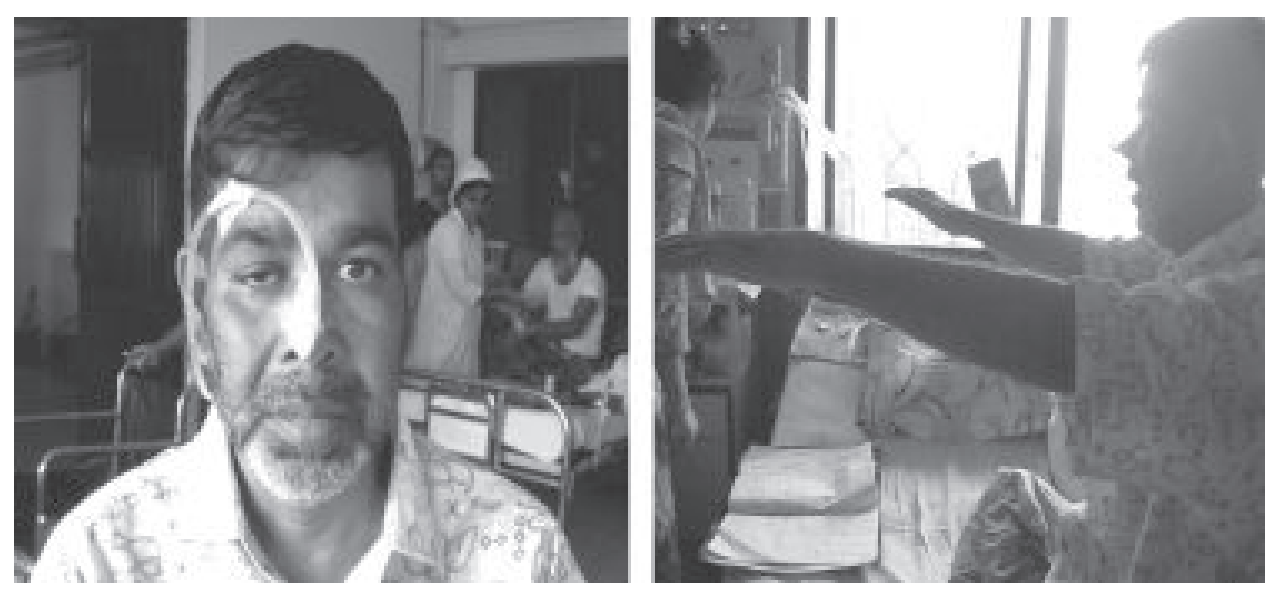

Fig-1: Pictorial profile of patient

Respiratory system examination revealed diminished breath sound and dull percussion note over left lower lung field. All other systemic examination were normal.

$\mathrm{His} \mathrm{Hb} \%$ was $12.9 \mathrm{gm} / \mathrm{dl}$, Total and differential white cell count was normal, Platelet count 2,34000/ cumm , ESR- $40 \mathrm{~mm}$ in $1^{\text {st }} \mathrm{hr}$. His fasting Blood Sugar was $6.1 \mathrm{mmol} / \mathrm{l}$ and after breakfast was 9.7 $\mathrm{mmol} / \mathrm{l}, \mathrm{HbA} 1 \mathrm{C}-6.1 \%$.Routine biochemical tests including renal function, liver function, electrolytes were normal.ECG was normal .Chest XR revealed opacities occupying left lung field with collapse of left lower lobe as evidenced by elevation of left hemi diaphragm(Fig-2).

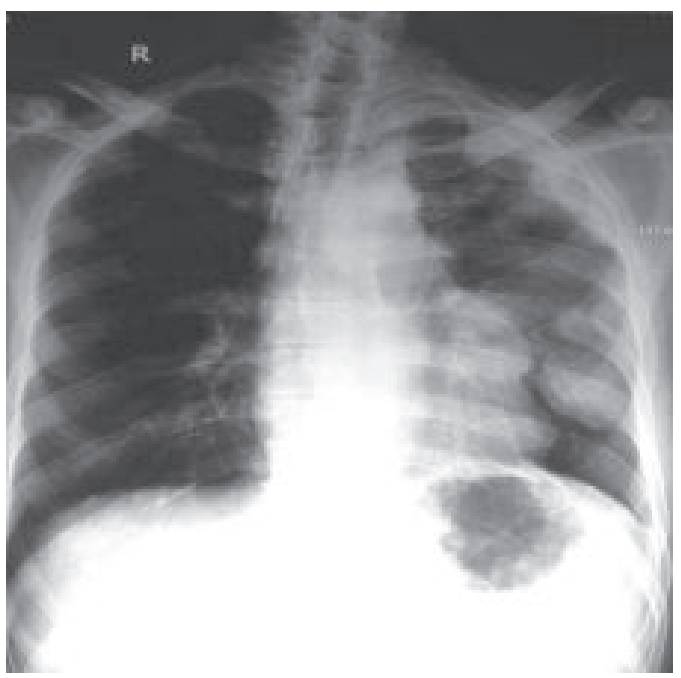

Fig-2: CXR PA showing opacities occupying left lung field with collapse of left lower lobe
No abnormality was detected in MRI of brain as well as MRI of cervical spine.

We performed standard repetitive nerve stimulation (RNS) test, which is one of the most sensitive diagnostic tests in patients with NMJ disorders, to evaluate patient's muscle weakness. We first performed nerve conduction study (NCS) in upper and lower limbs that were normal in distal latency, velocity and amplitude. Repetitive nerve stimulation (RNS) study of facial and ulnar nerve showed significant decremental response from $6^{\text {th }}$ onward; thus suggesting neuromuscular junction disorder(Fig-3). After these procedures, needle electromyography was done in upper and lower limb muscles; that was normal in every parameter.

AChR-ab or Voltage gated calcium channel antibody was not tested. To evaluate the findings in the chest $\mathrm{x}$-ray and to search for the presence of thymoma, chest CT scan with contrast was done. No evidence of thymoma was noticed.

CT scan of chest revealed a broad non- enhancing based soft tissue mass suggestive of consolidation(?Primary) with pleural base in left para vertebral, left anterior chest wall, anterior mediastinum, extending up to chest wall in left para sternal region and right para tracheal lymphadenopathy(Fig-4).

FNAC from subcutaneous nodule over sternum was done by orthopedic surgeons. Smear shows 
anaplastic cells with scanty cytoplasm round to oval hyperchromatic nuclei with coarse cromatin and inconspicuous nucleoli. These cella are arranged in clusters, rossetes and singly; compatible with metastatic small cell carcinoma of lung and hstopathology report was positive for malignant cells; compatible with metastatic small cell carcinoma of lung(Fig-5).

Specialist consultation was taken from oncologist, and a CT guided FNAC from lung lesion was done, which was positive for malignancy suggestive of SCLC.
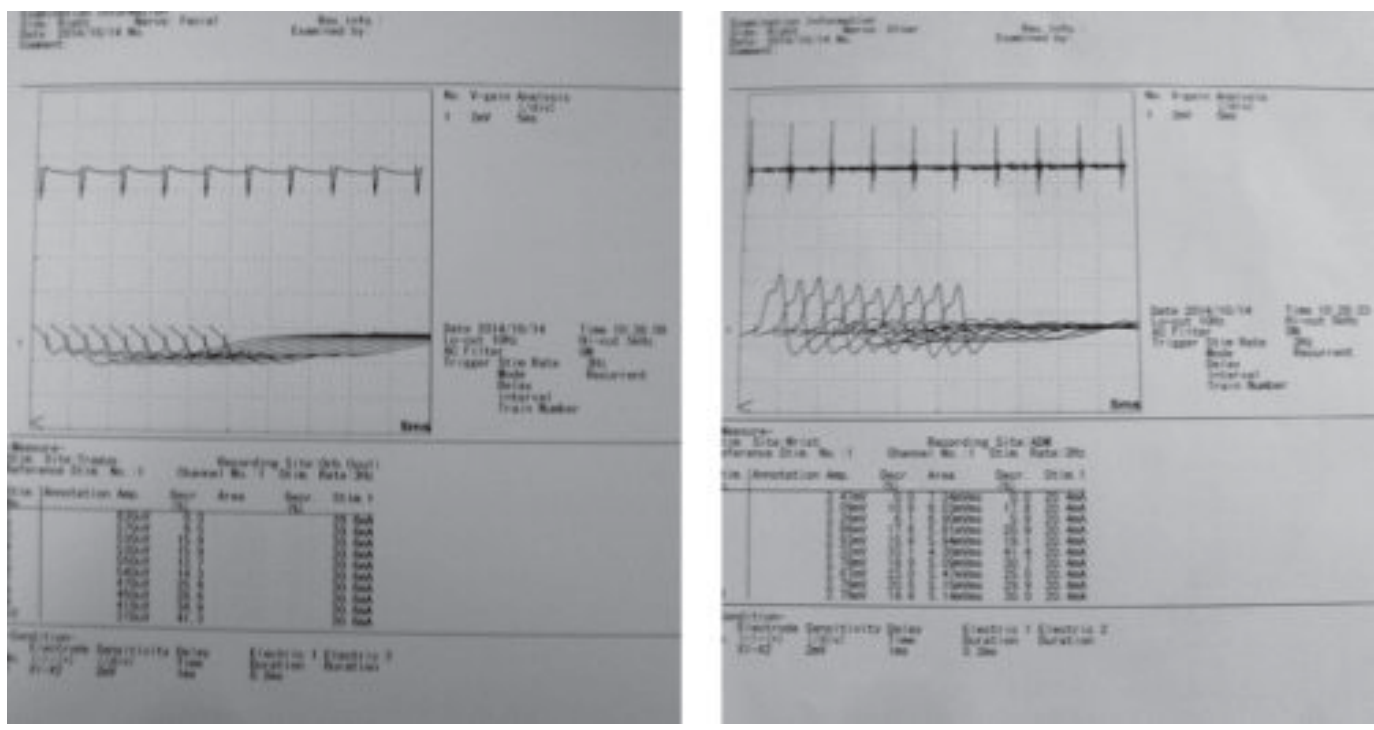

Fig-3: Repetitive nerve stimulation (RNS) study data of facial and ulnar in reported patient.
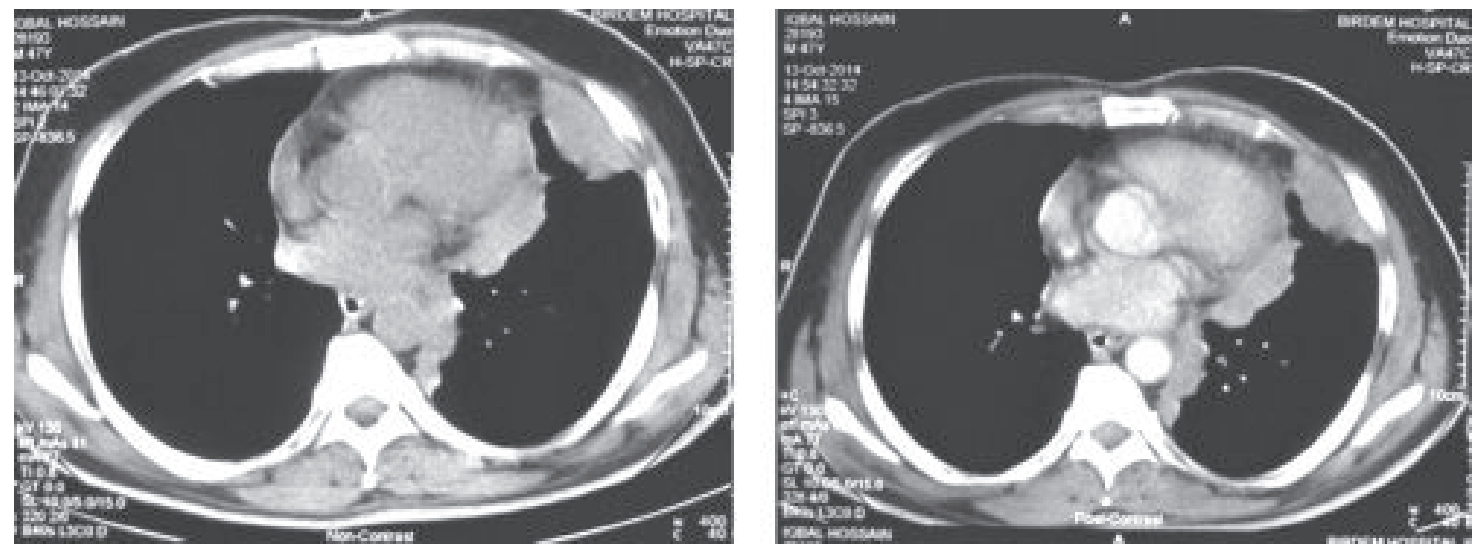

Fig-4: CT scan of chest revealed a broad non- enhancing based soft tissue mass and right para tracheal lymphadenopathy 

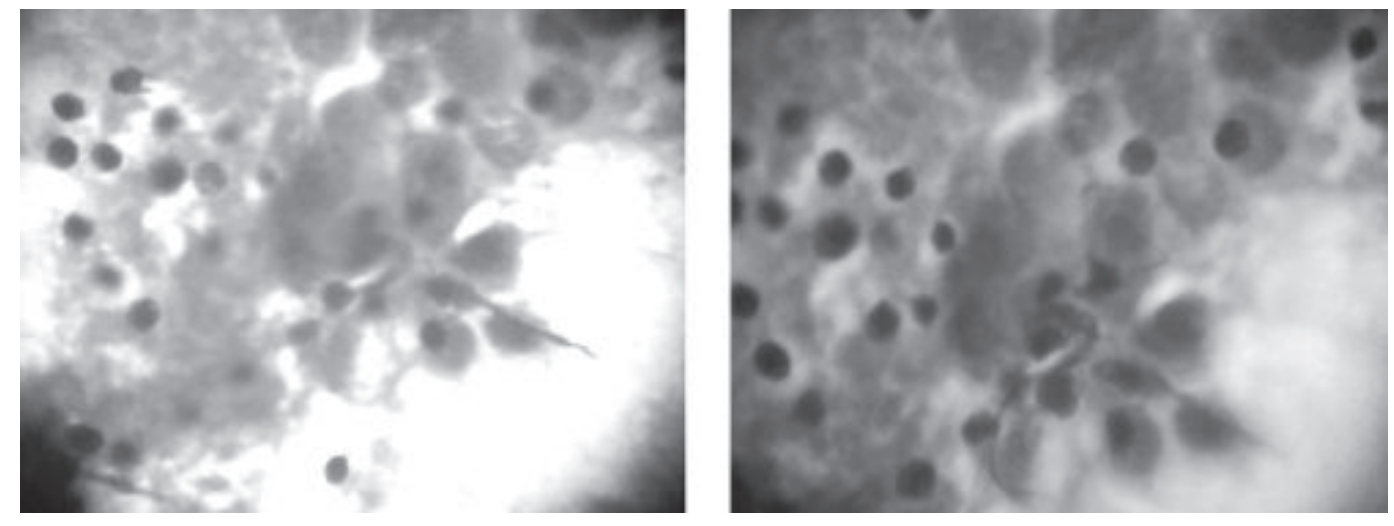

Fig.-5: Smear showed anaplastic cells compatible with metastatic small cell carcinoma of lung

\section{Discussion:}

Paraneoplastic syndromes are common findings in lung cancer. They often are incidental

findings serving as a harbinger to the underlying disease. They comprise syndromes involving the neuromuscular junction, vascular, hematologic, and metabolic syndromes as well as connective tissue and skeletal tissue disorders ${ }^{6}$. Paraneoplastic disorders are diagnosed in up to $15 \%$ of patients with the highest incidence occurring in NSCLC. Neurological paraneoplastic syndromes have an incidence of $0.01 \%$ of cancer patients, often imposing a burden on the patient's ability to carry out their activities of daily living ${ }^{7}$. These neurological syndromes comprise syndromes such as LambertEaton myasthenic syndrome (LEMS), limbic encephalopathy, polyneuropathy, cerebellar degeneration, opsoclonus-myoclonus, and autonomic neuropathy 6,7 .

Traditionally myasthenia gravis has been associated with several autoimmune diseases including lupus erythematosus, rheumatoid arthritis, diabetes mellitus type 1, Hashimoto's thyroiditis, grave's disease, and part of the paraneoplastic spectrum in thymic diseases such as thymoma ${ }^{8}$.

The correlation between myasthenia gravis and primary lung carcinomas has not been established, as has clearly been defined for Lambert-Eaton syndrome and small cell carcinoma of the lung. There are few reports on primary lung carcinomas which complicate $M G$, in the medical literature ${ }^{9-14}$.
According to literature review, there are two types of association between lung cancer and MG. The more common is the occurrence of lung cancer in MG patients after many years of treatment that can be a coincidental finding ${ }^{9-17}$. Another type is presentation of cancer simultaneously with MG, which is a rarer report ${ }^{17-19}$.

Only a few cases showing combined MG and SCLC features have been reported ${ }^{20,21}$. They were male and aged 49 to 56 . Three cases were seronegative. In two cases, SCLC was found at the time when the diagnosis of MG was made. In Myoshi's case, SCLC was found 18 months after the diagnosis of MG. Three cases had classical oculo-proximal muscle weakness of MG. ${ }^{21}$ One case had bulbar weakness. One case presented with MG crisis ${ }^{22}$.

Anti-acetylcholine receptor antibodies (Anti-AChR abs) are the causative agents in myasthenia gravis $^{23}$. These antibodies affect neuromuscular transmission by functional impairment of the AChR and accelerated degradation and complement activation at the $\mathrm{AChR}$, ultimately leading to the loss of neurotransmission. $20 \%$ of these individuals, however, are referred to as seronegative patients. These individuals do not possess the classic antiAChR abs rather they possess Anti-MuSK abs, an antibody towards argin/MuSK signaling pathway responsible for the functional maintenance of the postsynaptic neuromuscular junction ${ }^{24}$.

The standard diagnosis of myasthenia gravis relies on the reliable demonstration of anti-AChR abs or anti-MuSK abs; however, these may not always be 
available. Electrophysiologic testing through repetitive nerve stimulation may be used alternatively to detect a neuromuscular transmission defect (sensitivity 95-99\%).In 1992, Chini et al. demonstrated the potential for small cell lung carcinoma, non-small lung carcinoma, and neuroblastomas to express the á3 subunit $n A C h R^{25}$. They further established the cross reactivity of autoantibodies against á3-nAChR against the a1 nAChR ${ }^{25-27}$.In our case, considering the diagnosis of SCLC and cost of testing for antiACR abs or anti-MuSK abs, these tests were not done.

In conclusion, this case was a typical MG but his symptoms were the only clinical presentation of his underlying lung cancer; it means that MG can be a paraneoplastic syndrome, such as Lambert-Eaton myasthenic syndrome.

\section{References:}

1. Evoli A, Batocchi AP, Tonali P, Marciano M. Risk of cancer in patients with myasthenia gravis. Ann N Y Acad Sci. 1998;841:742-5.

2. McCart JA, Gaspar L, Inculet R, Casson AG. Predictors of survival following surgical resection of thymoma. J Surg Oncol. 1993;54(4):233-8.

3. Monden Y, Uyama T, Kimura S, Taniki T. Extrathymic malignancy in patients with myasthenia gravis. Eur J Cancer. 1991;27(6):745-7

4. Papatestas AE, Osserman KE, Kark AE. The relationship between thymus and oncogenesis.A study of the incidence of non thymic malignancy in myasthenia gravis. $\mathrm{Br} \mathrm{J}$ Cancer. 1971;25(4):635-45.

5. Levin N, Abramsky O, Lossos A, Karussis D, Siegal T, Argov Z, et al. Extrathymic malignancies in patients with myasthenia gravis. J Neurol Sci. 2005;237(1-2):39-43.

6. S. Heinemann, P. Zabel, and H. P. Hauber, "Paraneoplastic syndromes in lung cancer," Cancer Therapy, vol. 6, pp. 687-698, 2008.

7. A. M. Patel, D. G. Davila, and S. G. Peters, "Paraneoplastic syndromes associated with lung cancer," Mayo Clinic Proceedings, vol.
68, no. 3, pp. 278-287, 1993. View at Publisher View at Google Scholar .

8. B. M. Conti-Fine, M. Milani, and H. J. Kaminski, "Myasthenia gravis: past, present, and future," Journal of Clinical Investigation, vol. 116, no. 11, pp. 2843-2854, 2006. View at Publisher · View at Google Scholar :

9. Evoli A, Batocchi AP, Tonali P, Marciano M. Risk of cancer in patients with myasthenia gravis. Ann N Y Acad Sci. 1998;841:742-5.

10. McCart JA, Gaspar L, Inculet R, Casson AG. Predictors of survival following surgical resection of thymoma. J Surg Oncol. 1993;54(4):233-8.

11. Monden $\mathrm{Y}$, Uyama T, Kimura S, Taniki T. Extrathymic malignancy in patients with myasthenia gravis. Eur J Cancer. 1991;27(6):745-7.

12. Papatestas AE, Osserman KE, Kark AE. The relationship between thymus and oncogenesis.A study of the incidence of non thymic malignancy in myasthenia gravis. $\mathrm{Br} \mathrm{J}$ Cancer. 1971;25(4):635-45.

13. Levin N, Abramsky O, Lossos A, Karussis D, Siegal T, Argov Z, et al. Extrathymic malignancies in patients with myasthenia gravis. J Neurol Sci. 2005;237(1-2):39-43.

14. Carsons $\mathrm{S}$. The association of malignancy with rheumatic and connective tissue diseases. Semin Oncol. 1997;24(3):360-72.

15. Souadjian JV, Enriquez P, Silverstein MN, Pepin JM. The spectrum of diseases associated with thymoma. Coincidence or syndrome? Arch Intern Med. 1974;134(2): 374-9.

16. Sakamaki Y, Yoon HE, Oda N. Non-small-cell lung cancer associated with non-thymomatous myasthenia gravis. Jpn J Thorac Cardiovasc Surg. 2006;54(5):207-11

17. Miyoshi R, Yamaji Y, Shima S, Fujita J, Okada $\mathrm{H}$, Takahara J. A case of small cell lung cancer that developed during therapy for myasthenia gravis. Nihon Kyobu Shikkan Gakkai Zasshi. 1995;33(4):456-62. 
18. Kataoka K, Fujiwara T, Matsuura M, Seno N. A case of simultaneously operated primary multiple lung cancers with non-thymomatous myasthenia gravis. Japanese Journal of Lung Cancer. 2009;49(3):273-7.

19. Peltier AC, Black BK, Raj SR, Donofrio P, Robertson D, Biaggioni I. Coexistent autoimmune autonomic ganglionopathy and myasthenia gravis associated with non-smallcell lung cancer. Muscle Nerve. 2010;41(3):416-9.

20. Carsons $\mathrm{S}$. The association of malignancy with rheumatic and connective tissue diseases. Semin Oncol. 1997;24(3):360-72.

21. Souadjian JV, Enriquez P, Silverstein MN, Pepin JM. The spectrum of diseases associated with thymoma. Coincidence or syndrome? Arch Intern Med. 1974;134(2): 374-9.

22. Sakamaki Y, Yoon HE, Oda N. Non-small-cell lung cancer associated with non-thymomatous myasthenia gravis. Jpn J Thorac Cardiovasc Surg. 2006;54(5):207-11.

23. A. C. Peltier, B. K. Black, S. R. Raj, P. Donofrio, D. Robertson, and I. Biaggioni, "Coexistent autoimmune autonomic ganglionopathy and myasthenia gravis associated with non-small-cell lung cancer," Muscle and Nerve, 2010; 41( 3) 416-19.
24. T. Kirchner, S. Tzartos, F. Hoppe, B. Schalke, $\mathrm{H}$. Wekerle, and H. K. Muller-Hermelink, "Pathogenesis of myasthenia gravis: acetylcholine receptor-related antigenic determinants in tumor-free thymuses and thymic epithelial tumors," American Journal of Pathology. 1988; 130 (2)268-80.

25. B. Chini, F. Clementi, N. Hukovic, and E. Sher, "Neuronal-type á-bungarotoxin receptors and the á5-nicotinic receptor subunit gene are expressed in neuronal and nonneuronal human cell lines," Proceedings of the National Academy of Sciences of the United States of America, 1992; 89(5):1572-76.

26. Mihovilovic,M, Hulette C, Mittelstaedt J, Austin C, and Roses AD, "Nicotinic neuronal acetylcholine receptor á-3 subunit transcription in normal and Myasthenic thymus," Annals of the New York Academy of Sciences. 1993;681: 83-96.

27. Mihovilovic M and Butterworth-Robinette J.,"Thymic epithelial cell line expresses transcripts encoding á- 3 , á- 5 and â-4 subunits of acetylcholine receptors, responds to cholinergic agents and expresses choline acetyl transferase. An in vitro system to investigate thymic cholinergic mechanisms," Journal of Neuroimmunology.2001; 117(1-2) 58-67. 